\title{
Desempenho de quatro genótipos de soja-hortaliça em dois anos agrícolas
}

\author{
Renata Castoldi'; Hamilton César de O Charlo'; Pablo F Vargasi ${ }^{1}$ Leila T Braz ${ }^{1}$; José Lindorico de \\ Mendonça²; Mercedes C Carrão-Panizzi ${ }^{3}$ \\ ${ }^{1}$ UNESP-FCAV, Dep ${ }^{\text {to }}$ Produção Vegetal, Rodov. Prof. Paulo Donato Castellane s/n, 14884-900 Jaboticabal-SP; ${ }^{2}$ Embrapa Hortaliças, C. \\ Postal 218, 70359-970 Brasília-DF; ${ }^{3}$ Embrapa Soja, C. Postal 231, 86001-970 Londrina-PR; rcastoldi@ gmail.com
}

\section{RESUMO}

Com o objetivo de avaliar o desempenho de quatro genótipos de soja-hortaliça, em dois anos agrícolas, foi instalado um ensaio, em área da UNESP-FCAV, Campus de Jaboticabal-SP. O delineamento experimental adotado foi de blocos casualizados, com quatro genótipos e cinco repetições, para cada ano agrícola. Cada parcela experimental foi constituída por quatro linhas de plantio, com $3 \mathrm{~m}$ de comprimento, dispostas no espaçamento de $0,10 \mathrm{~m}$ entre plantas e $0,60 \mathrm{~m}$ nas entrelinhas, sendo consideradas para avaliação 20 plantas por parcela, das duas linhas centrais. As sementes foram semeadas em bandejas de poliestireno expandido de 128 células, contendo substrato Plantmax Hortaliças ${ }^{\circledR}$. O transplante ocorreu dez dias após a semeadura, sendo que o solo já estava devidamente preparado, conforme recomendações para a cultura. A colheita foi realizada quando as vagens estavam em estádio reprodutivo R6. Avaliaram-se os genótipos: JLM003; JLM010; JLM018 e CNPSoI quanto às características: altura de inserção da primeira vagem, número médio de vagens por planta, número médio de sementes por vagem, produção de vagens por planta, massa fresca de 100 sementes e produtividade estimada de grãos imaturos. De acordo com os resultados obtidos, concluiu-se que, dentre os genótipos avaliados, JLM003, JLM010 e CNPSoI foram os mais produtivos, e quando semeados em dezembro apresentam produtividades maiores do que quando semeados em setembro.

Palavras-chave: Glycine max, produtividade, épocas de semeadura.

\begin{abstract}
Performance of four vegetable soybean genotypes in two agricultural years

The performance of vegetable soybean genotypes was evaluated in two years, in the experimental area of Universidade Estadual de São Paulo, São Paulo State, Brazil. The experimental design was of randomized blocks, with four genotypes and five replications per each year. Plots comprised of four rows, with three meters in length and the plants were arranged with a plant spacing of $0.10 \mathrm{~m}$ and $0.60 \mathrm{~m}$ between rows, where 20 plants per plot were studied. Seeds were sown in expanded polystyrene trays with 128 pyramidal cells, with the substrate Plantmax Hortaliças ${ }^{\circledast}$. Transplanting was performed ten days after sowing, in a soil previously fertilized as recommended for the crop. Harvesting was performed when pods reached the reproductive stage R6. The genotypes JLM003; JLM010; JLM018 and CNPSoI were evaluated to measure the insertion height of first pod, mean number of pods per plant, mean number of seeds per pod, production of pods per plant, fresh weight of 100 grains and total yield of immature grains. Genotypes JLM003, JLM010 and CNPSoI were the most productive and sowing date in December showed greater yield than sowing in September.
\end{abstract}

Keywords: Glycine max, yield, seasons of seeding.

(Recebido para publicação em 26 de fevereiro de 2008; aceito em 7 de maio de 2009)

(Received in February 26, 2008; accepted in May 7, 2009)

A soja-hortaliça pertence ao mesmo gênero da soja-grão (Glycine max (L.) Merril) e à mesma família (Fabaceae), porém os grãos são consumidos quando imaturos e ocupam $80 \%$ a $90 \%$ da largura das vagens, o que corresponde ao estádio R6 (Konovsky \& Lumpkin, 1990).

Em comparação com a soja-grão, os grãos das cultivares de soja-hortaliça são maiores e considerados melhores em sabor e textura; necessitam menor tempo de cozimento, devido principalmente aos níveis mais altos de ácido fítico, o que torna os grãos mais tenros e de cocção rápida (Konovsky \& Lumpkin, 1990); possuem teor elevado de aminoácidos, em especial o ácido glutâmico, responsável pelo melhor sabor dos grãos; apresentam conteúdos de amido e sacarose elevados, tornando os grãos mais adocicados e contêm teores reduzidos dos oligossacarídeos rafinose e estaquiose, de difícil digestão (Mendonça \& CarrãoPanizzi, 2008). Além disso, destacam-se como fonte de isoflavonas, apresentam reduzido teor de óleo $(5,7 \%)$, elevado teor de proteínas $(13 \%)$, ausência de colesterol e gordura hidrogenada e teores razoáveis de minerais, fósforo, cálcio e vitaminas B1 e B2 (Shanmugasundaram \& Yan, 2004).

Atualmente, Japão, China, Coréia e Taiwan são os principais produtores e consumidores desse tipo de alimento (Carrão-Panizzi, 2006), sendo no Brasil, em especial no estado de São Paulo, o consumo do petisco de soja-hortaliça (edamame) restrito aos descendentes de orientais, destacando-se japoneses, chineses e coreanos.

No Brasil a soja tem recebido atenção pública considerável por seus po- tenciais benéficos à saúde humana, prevenindo doenças crônicas (CarrãoPanizzi et al., 2003), devido em especial à presença das isoflavonas, compostos fenólicos, envolvidos em atividades anticarcinogênicas, redução da perda de massa óssea e diminuição do colesterol do sangue (Góes-Favoni et al., 2004).

A soja-hortaliça pode ser uma alternativa natural na reposição hormonal, bem como um alimento de grande importância na dieta humana, especialmente na feminina. Porém, não existem estudos sobre o comportamento de genótipos de soja-hortaliça em diferentes épocas de estabelecimento da cultura, para as condições brasileiras.

Devido a essa falta de estudos, aliada à grande importância nutracêutica da soja-hortaliça, o presente trabalho teve por objetivo avaliar a influência de dife- 
Tabela 1. Características de produção de quatro genótipos de soja-hortaliça, em duas épocas de semeadura (average of four genotypes of vegetable soybean, in two sowing dates). Jaboticabal, UNESP-FCAV, 2006.

\begin{tabular}{|c|c|c|c|c|c|c|}
\hline \multirow[b]{2}{*}{ Genótipos } & \multicolumn{6}{|c|}{ Características } \\
\hline & $\begin{array}{l}\text { AIPV } \\
(\mathrm{cm})^{1}\end{array}$ & NVP $^{2}$ & NMGV $^{3}$ & $\begin{array}{l}\text { PVP } \\
(\mathrm{g})^{4} \\
\end{array}$ & $\begin{array}{l}\text { MF100 } \\
(\mathrm{g})^{5}\end{array}$ & $\begin{array}{c}\text { PTE } \\
\left(\mathrm{t} \mathrm{ha}^{-1}\right)^{6}\end{array}$ \\
\hline JLM010 & $11,8 a b$ & $27,9 \mathrm{c}$ & $2,0 a b$ & $78,2 \mathrm{a}$ & 77,6 a & $8,2 \mathrm{a}$ \\
\hline JLM003 & $13,0 \mathrm{a}$ & $42,8 \mathrm{~b}$ & $2,2 \mathrm{a}$ & 84,6 a & $57,9 a$ & 9,4 a \\
\hline JLM018 & $10,1 \mathrm{~b}$ & $58,4 a$ & $1,8 \mathrm{~b}$ & 66,7 a & $40,2 \mathrm{a}$ & 6,6 a \\
\hline CNPSol & $10,1 \mathrm{~b}$ & $48,0 \mathrm{~b}$ & $2,0 \mathrm{ab}$ & $70,9 \mathrm{a}$ & $54,4 \mathrm{a}$ & $9,1 \mathrm{a}$ \\
\hline \multicolumn{7}{|c|}{ Épocas de semeadura } \\
\hline Dezembro 2004 & 16,9 a & $45,9 a$ & $2,1 \mathrm{a}$ & $78,7 \mathrm{a}$ & 55,6 a & $9,3 a$ \\
\hline Setembro 2005 & $5,6 \mathrm{~b}$ & 42,6 a & $1,9 b$ & $71,5 \mathrm{a}$ & $59,4 a$ & 7,4 a \\
\hline
\end{tabular}

${ }^{1} \mathrm{AIPV}=$ Altura de inserção da primeira vagem; ${ }^{2} \mathrm{NVP}=$ Número de vagens por planta $;{ }^{3} \mathrm{NMGV}=$ Número médio de grãos por vagem; ${ }^{4} \mathrm{PVP}=$ Produção de vagens por planta; ${ }^{5} \mathrm{MF}_{100}=$ Massa fresca de 100 grãos; ${ }^{6} \mathrm{PTE}=$ Produtividade total estimada de grãos imaturos por hectare $\left({ }^{1} \mathrm{AIPV}=\right.$ insertion height of first pod; ${ }^{2} \mathrm{NVP}=$ number of pods per plant; ${ }^{3} \mathrm{NMGV}=$ mean number of grains per pod; ${ }^{4} \mathrm{PVP}=$ production of pods per plant; ${ }^{5} \mathrm{MF}_{100}=$ fresh weight of 100 grains; ${ }^{6} \mathrm{PTE}=$ total estimate yield of immature grains); Médias seguidas pela mesma letra não diferem significativamente entre si, teste de Tukey, $\mathrm{p}<0,05$ (means followed by the same letter do not differ significantly from each other, Tukey's test, $\mathrm{p}<0,05$ ).

Tabela 2. Altura de inserção da primeira vagem em quatro genótipos de soja-hortaliça, em duas épocas de semeadura (insertion height of first pod in four genotypes of vegetable soybean, in two sowing dates). Jaboticabal, UNESP-FCAV, 2006.

\begin{tabular}{lrrrr}
\hline Épocas de & \multicolumn{4}{c}{ Altura de inserção da primeira vagem (cm) } \\
\cline { 2 - 5 } semeadura & JLM010 & JLM003 & JLM018 & CNPSOI \\
\hline Dezembro 2004 & $16,7 \mathrm{Ba}$ & $20,5 \mathrm{Aa}$ & $14,5 \mathrm{Ba}$ & $15,9 \mathrm{Ba}$ \\
Setembro 2005 & $6,8 \mathrm{Ab}$ & $5,5 \mathrm{Ab}$ & $5,7 \mathrm{Ab}$ & $4,4 \mathrm{Ab}$ \\
\hline
\end{tabular}

Médias seguidas por letras maiúsculas nas linhas e minúsculas nas colunas, não diferem entre si, pelo Teste de Tukey, a 5\% de probabilidade (means followed by the same capital letter in the row and small letter in the column do not differ significantly, according to Tukey's test, $\mathrm{p}<0,05)$.

rentes anos agrícolas, nas características agronômicas, em quatro genótipos de soja-hortaliça.

\section{MATERIAL E MÉTODOS}

O experimento foi conduzido em campo, na área experimental do Setor de Olericultura e Plantas Aromático-Medicinais, nas dependências da UNESPFCAV em Jaboticabal. O clima da região, segundo a classificação de Köppen, é do tipo Aw com transição para Cwa, e o solo foi classificado como sendo Latossolo eutroférrico (Embrapa, 1999).

O experimento foi conduzido em duas épocas de semeadura em dois anos agrícolas, sendo o primeiro ano agrícola compreendido entre 18 de dezembro de 2004 a 17 de abril de 2005, e o segundo ano agrícola de 18 de setembro de 2005 a 15 de janeiro de 2006. deradas para avaliação 20 plantas por parcela, das duas linhas centrais, o que correspondia a $1,20 \mathrm{~m}^{2}$ da área útil.

Os genótipos utilizados foram previamente testados em estudos anteriores e os que apresentaram melhores características para o consumo como hortaliça foram utilizados no atual experimento e constaram de JLM003 (porte médio; massa seca de 100 sementes $=30$ gramas; flor de coloração roxa; hilo claro; grão bege e originário de coleta no Distrito Federal); JLM010 (porte médio; massa seca de 100 sementes $=41$ gramas; flor de coloração branca; hilo e grão claros, e originário da AVRDC (Taiwan)); JLM018 (porte alto; massa seca de 100 sementes $=24,8$ gramas; flor de coloração roxa; hilo marrom; grão creme e originário do CENARGEN) e CNPSoI (porte médio; massa seca de 100 sementes = 27,8 gramas; hilo claro e originário da Embrapa-Soja).

Devido ao intenso ataque de pombos em plantios anteriores com semeadura direta, optou-se pela formação das mudas, utilizando-se de bandejas de poliestireno expandido, com capacidade para 128 células, colocando-se uma semente por célula, já inoculada na proporção de 500 gramas de inoculante, que contêm Bradyrhizobium, para cada 50 $\mathrm{kg}$ de sementes de soja-hortaliça.

As mudas foram transplantadas aos dez dias após a semeadura, em solo anteriormente preparado e adubado, conforme os resultados da análise do solo e a recomendação de Raij et al., (1997) para a cultura da soja. Para tanto, foram aplicados em adubação de plantio, $40 \mathrm{~kg} \mathrm{ha}^{-1}$ de $\mathrm{P}_{2} \mathrm{O}_{5}$ e $60 \mathrm{~kg} \mathrm{ha}^{-1}$ de $\mathrm{K}_{2} \mathrm{O}$, utilizando superfosfato simples e cloreto de potássio como fonte, respectivamente. Sendo que o $\mathrm{K}_{2} \mathrm{O}$ foi parcelado, aplicando-se metade da dose no sulco de plantio e a outra metade em adubação de cobertura, realizada 30 dias após o transplante.

A colheita foi realizada quando as vagens estavam em estádio reprodutivo R6, tendo como referência a escala de Fehr \& Caviness, adaptada por Costa \& Marchezan (1982). Com a ajuda de um facão, cortaram-se as plantas acima da superfície do solo, levaram-nas ao laboratório e retiraram-se as vagens.

Foram avaliados a altura de inserção da primeira vagem, número de vagens 
por planta, número médio de grãos por vagem, produção de vagens por planta, massa fresca de 100 grãos e a produtividade estimada de grãos imaturos por hectare, calculado através da produção por área útil de parcela $\left(1,20 \mathrm{~m}^{2}\right)$ e estimada a produção por hectare.

Realizou-se análise de variância para cada uma das épocas e posteriormente, a análise conjunta dos dados sendo as médias comparadas pelo teste de Tukey, a $5 \%$ de probabilidade.

\section{RESULTADOS E DISCUSSÃO}

Houve interação entre os genótipos e anos agrícolas apenas para as características altura de inserção da primeira vagem (Tabela 2) e massa fresca de 100 grãos (Tabela 3). Para as demais características, os dados serão discutidos separadamente.

Para altura de inserção da primeira vagem, a semeadura em dezembro proporcionou médias superiores às da semeadura em setembro (Tabela 2). O cultivo em setembro (88 dias) proporcionou florescimento precoce, fato que refletiu em um ciclo da cultura 32 dias menor que o cultivo em dezembro (120 dias). Esse ciclo precoce, que pode ter sido ocasionado pela diferença fotoperiódica das épocas de cultivo, provocou um menor crescimento vegetativo e conseqüentemente uma inserção mais baixa das vagens. Em relação aos genótipos, verificou-se diferença entre eles para essa característica, apenas para a semeadura feita em dezembro, onde o genótipo JLM003 apresentou a maior média $(20,5 \mathrm{~cm})$.

Apesar de no Brasil, as atuais colheitadeiras não serem preparadas para colherem grãos verdes, ou seja, com alto teor de umidade (acima de $14 \%$ de umidade) é de fundamental importância selecionar plantas com alta inserção de vagens facilitando, futuramente, a colheita desse tipo de soja com máquinas.

O genótipo JLM010 apresentou o menor número de vagens por planta $(27,9)$, não sendo influenciado pela época de estabelecimento da cultura (Tabela 1). Verifica-se que, apesar do baixo número de vagens por planta, o genótipo JLM010 apresentou o maior valor de massa fresca de 100 grãos $(77,6$

Tabela 3. Massa fresca de 100 grãos de quatro genótipos de soja-hortaliça, em duas épocas de semeadura (average weight of 100 grains ( $\mathrm{g}$ ) of four genotypes of vegetable soybean, in two sowing dates). Jaboticabal, UNESP-FCAV, 2006.

\begin{tabular}{llccc}
\hline Épocas de & \multicolumn{4}{c}{ Massa fresca de 100 grãos (g) } \\
\cline { 2 - 5 } semeadura & JLM010 & JLM003 & JLM018 & CNPSOI \\
\hline Dezembro 2004 & $68,2 \mathrm{Ab}$ & $62,2 \mathrm{Aa}$ & $43,0 \mathrm{Ba}$ & $49,1 \mathrm{Bb}$ \\
Setembro 2005 & $87,0 \mathrm{Aa}$ & $53,7 \mathrm{Ba}$ & $37,4 \mathrm{Ca}$ & $59,7 \mathrm{Ba}$ \\
\hline
\end{tabular}

Médias seguidas por letras maiúsculas nas linhas e minúsculas nas colunas, não diferem entre si, pelo Teste de Tukey, $\mathrm{p}<0,05$ (means followed by the same capital letter in the row and small letter in the column do not differ significantly, according to Tukey's test, $\mathrm{p}<0,05$ ).

g), ou seja, característica desejável à soja-hortaliça, já que grãos graúdos facilitam o cozimento e o seu consumo (Carrão-Panizzi, 2006).

Estes valores estão próximos aos encontrados por Charlo et al. (2008), que avaliaram duas cultivares de sojahortaliça de ciclo precoce (JLM010 e CNPSOI) em diferentes densidades, no período de setembro a dezembro, e verificaram respectivamente 28,8 e 47,3 vagens por planta, para as cultivares JLM010 e CNPSOI, sendo que à medida que diminuiu-se a densidade, aumentou o número de vagens por planta.

O genótipo JLM018 diferiu dos demais, apresentando o menor número médio de grãos por vagem $(1,8)$ (Tabela 1). Os genótipos de soja-hortaliça semeados em dezembro apresentaram maior número de grãos por vagem $(2,1)$. Mais uma vez verifica-se a interferência negativa da precocidade dos genótipos quando se cultivou em setembro. Apesar do cultivo em dezembro permanecer no campo 32 dias a mais que o cultivo de setembro, gerando mais custos ao produtor e estando disponível para comercialização mais tardiamente, essa diferença é compensada, pois refletiu em maior produção de fotoassimilados e, conseqüentemente, maior número de grãos por vagem.

Em relação à produção de vagens por planta, verificou-se que não houve diferença estatística entre os genótipos avaliados (Tabela 1). Da mesma forma, devido à grande semelhança dos dados meteorológicos em setembro e dezembro, exceto fotoperíodo, a produção de vagens por planta não foi influenciada pela época de semeadura da cultura.

Houve interação entre os genótipos e épocas de estabelecimento da cultura para a massa fresca de 100 grãos, sendo que, para a semeadura em dezembro, as maiores médias dessa característica foram observadas nos genótipos JLM010 (68,2 g) e JLM003 (62,2 g). Para a semeadura em setembro, o genótipo JLM010 $(87,0 \mathrm{~g})$ foi o que apresentou o melhor desempenho (Tabela 3).

Viana et al., (2005), avaliando cinco genótipos de soja-hortaliça (AVRDC 7; AVRDC 8; BRS 155; JLM 003; JLM 004) no período de novembro de 2003 a abril de 2004, no município de Areia-PB, verificaram valor semelhante de massa fresca de 100 sementes $(64,5 \mathrm{~g} / 100$ sementes verdes) ao encontrado no presente trabalho para a cultivar JLM003, semeada no período de dezembro a março.

Nota-se que em ambos os cultivos, independente da época de semeadura, o genótipo JLM010 demonstra seu potencial produtivo, pois a massa fresca de 100 grãos foi semelhante à encontrada no trabalho de Charlo et al. (2008) e Castoldi et al. (2006).

Para a produtividade total estimada de grãos imaturos por hectare, o genótipo JLM003 (9,4 $\left.\mathrm{t} \mathrm{ha}^{-1}\right)$ foi o que apresentou a maior média, contudo não diferiu dos genótipos CNPSoI $\left(9,1 \mathrm{tha}^{-1}\right)$, JLM010 (8,2 t ha $\left.{ }^{-1}\right)$ e JLM018 (6,6 t ha-1). Não houve influencia da época de semeadura da cultura para tal característica, mesmo em condições fotoperiódicas diferentes.

As baixas produções obtidas no experimento de Costa et al., (2005), quando comparadas com a produtividade estimada do atual experimento podem ser atribuídas aos fatores climáticos, uma vez que a estação de crescimento e desenvolvimento das plantas no experimento de Costa et al. (2005) foi inverno/ primavera, cuja temperatura mínima atingiu $13,3^{\circ} \mathrm{C}$ e no atual experimento foram de $18,96^{\circ} \mathrm{C}$ (setembro) e $19,48^{\circ} \mathrm{C}$ (dezem- 
bro), com temperatura máxima em torno de $30^{\circ} \mathrm{C}$, ou seja, temperatura ideal para crescimento e desenvolvimento da soja, de acordo com a Embrapa (2002). No entanto, por ser uma cultura nova e promissora, ainda faz-se necessário mais estudo sobre a soja-hortaliça em condições climáticas adversas, já que não houve variação climática abruptas entre as épocas estudadas.

Com base nos resultados pode-se verificar que dentre os genótipos avaliados, JLM003, JLM010 e CNPSOI são os mais promissores e o cultivo em dezembro apresenta melhor desempenho em relação a setembro.

\section{REFERÊNCIAS}

CARRÃO-PANIZZI MC. 2006. Edamame ou soja-hortaliça: fácil de consumir e muito saudável. Informe Agropecuário 27: 5964.

CARRÃO-PANIZZI MC; SIMÃO AS; KIKUCHI A. 2003. Efeitos de genótipos, ambientes e de tratamentos hidrotérmicos na concentração de isoflavonas agliconas em grãos de soja. Pesquisa Agropecuária Brasileira 38: 897-902.

CASTOLDI R; BRAZ LT; CHARLO HCO; CARRÃO-PANIZZI MC; MENDONÇA JL. 2006. Desempenho de genótipos de sojahortaliça, em Jaboticabal-SP. In: CONGRESSO BRASILEIRO DE OLERICULTURA, 46. Resumos... Goiânia: ABH (CD-ROM).
CHARLO HCO; CASTOLDI R; VARGAS PF; BRAZ LT; MENDONÇA JL. 2008. Desempenho de genótipos de soja-hortaliça de ciclo precoce [Glycine max (L.) Merril] em diferentes densidades. Ciência $e$ Agrotecnologia 32; 630-634.

COSTA JA; MARCHEZAN E. 1982. Características dos estádios de desenvolvimento da soja. Campinas: Fundação Cargill. 30p.

COSTA CA; MENDONÇA JL; FERNANDES KO. 2005. Avaliação de genótipos de soja para consumo como hortaliça em Montes Claros-MG. In: CONGRESSO BRASILEIRO DE OLERICULTURA, 45. Resumos... Fortaleza: ABH (CD-ROM).

EMPRESA BRASILEIRA DE PESQUISA AGROPECUÁRIA. Centro Nacional de Pesquisa de Solos. 1999. Sistema brasileiro de classificação de solos: produção de informação. Rio de Janeiro: EMBRAPA. $412 \mathrm{p}$.

EMPRESA BRASILEIRA DE PESQUISA AGROPECUÁRIA. 2002. Tecnologias de produção de soja - região central do Brasil 2003. Londrina: EMBRAPA. 199p.

GÓES-FAVONI SP; BELÉIA ADP; CARRÃOPANIZZI MC; MANDARINO JMG. 2004. Isoflavonas em produtos comerciais de soja. Ciência e Tecnologia dos Alimentos 24: 582-586.

KONOVSKY J; LUMPKIN TA. 1990. Edamame production and use: a global perspective. In: INTERNATIONAL CONFERENCE SOYBEAN PROCESSING AND UTILIZATION. Program and abstracts... Gongzhuling: Jilin Academy of Agricultural Science.
MENDONÇA JL; CARRÃO-PANIZZI MC. 2008, 23 de dezembro. Soja verde, sojahortaliça. Disponível em http:// www.unitins.br/ates/arquivos/Agricultura/ O l e r i c u l t u r a / S o j a \% 20 $\% 20$ Cultivo\%20como\%20Hortaliça.pdf.

RAIJ BV; CANTARELLA H; QUAGGIO JA; FURLANI AMC. 1997. Recomendações da adubação e calagem para o Estado de São Paulo. 2. ed. Campinas: IAC. 285 p. (Boletim Técnico, 100).

SHANMUGASUNDARAM S; YAN MR. 2004. Global expansion of high value vegetable soybean. In: WORLD SOYBEAN RESEARCH CONFERENCE, 7; INTERNATIONAL SOYBEAN PROCESSING AND UTILIZATION CONFERENCE, 4; BRAZILIAN SOYBEAN CONGRESS, 3. Proceedings... Foz do Iguassu: Embrapa Soja. p. 915-920.

UNESP (Universidade Estadual Paulista). 2008, 12 de dezembro. Dados meteorológicos. <Disponível em http:// www.exatas.fcav.unesp.br/estacao/est_tab _meteor_01_02.htm.

VIANA JS; BRUNO RLA; SOUZA LC; BRUNO GB; MENDONÇA JL; OLIVEIRA AP. 2005. Determinações morfológicas e produtivas de cultivares de soja-verde nas condições edafoclimáticas do município de Areia-PB. In: CONGRESSO BRASILEIRO DE OLERICULTURA, 45. Resumos... Fortaleza: ABH (CD-ROM). 